\title{
Pure and Applied Research as the Epicenter of Research in Engineering Education
}

\author{
Dr. Kehdinga George Fomunyam \\ Teaching and Learning Development Center, Mangosuthu University of Technology, Durban, South Africa.
}

\begin{abstract}
Engineers play a vital role in any country's development, contributing to and facilitating initiatives that drive economic growth, enhance infrastructures and inspire innovation essential for human survival. Research is an integral part of engineering and engineering education all over the world. Innovation essential for a country's growth would hardly be possible without research. There are various components of research and this study explores the role of pure and applied research as the focal point of research in engineering education. Pure and applied research are essential components of progress and growth in any economy and a vital aspect of engineering education in higher institutions all over the world. Research plays the vital role of equipping students, graduates and academia with the knowledge and skills necessary for initiating, nurturing and advancing innovation and upgrading existing systems. Both types of research foster knowledge advancement and practical problem solving which reflects the core of engineering in any society seeking consistent technological progress. This study explores both forms of research and evaluates their relevance to today's academia.
\end{abstract}

Keywords: Research, Engineering, Engineering Education, Pure Research, Applied Research

\section{INTRODUCTION}

Linköping University defines engineering education as dealing with teaching, learning and the development of knowledge in engineering in the broad sense. It is a discipline that fosters interest in students acquisition and expansion of knowledge in techniques, technology and various fields of technology and development of problem solving abilities. It focuses on utilizing knowledge to serve humanity's need and wants. Engineers are trained to be initiators and implementers of technological innovation and development (Falade, 2016). As such they are key to the economical and technological development of any country, therefore it is imperative that continuous and relevant training be made available to students of engineering. A key part of this training is research, which is an essential part of acquiring verifiable knowledge, vital for innovating and the proper functioning of engineering systems and processes. The National Academy of Sciences posits that the objective of research is to expand man's knowledge of the physical and biological world beyond common knowledge. It is an essential component in building knowledge and is required for students, academics, professionals and non- professionals alike and roughly $76 \%$ of basic research is conducted by universities.

Pure and applied classification is based on the goal of the research. Thus, the key difference between pure and applied research depends on their goal; pure research is driven by curiosity and is conducted without a specific goal in mind whereas applied research is conducted with the aim of solving a problem. The practice or application of both types of research ensures that certain gaps are filled and more reliable information is gleaned for the advancement of engineering innovation, systems and processes. On the other hand, applied research is designed to answer specific questions aimed at solving practical problems and acquiring new knowledge with specific commercial objectives in the form of procedures, products or services. Thorough research is generally required for effective solutions, systems and innovations to be engineered. Higher institutions have to be equipped with the necessary tools and facilities vital for conducting proper research to enable engineering graduates make impactful contributions that align with society's infrastructural and technological needs.

The goal of research in engineering is problem solving and bringing about improvement in theory and practice in various fields. Major contributors to engineering research around the world include governments, private business and academia. This study focuses on the impact of academia's research on engineering education and examines the vital role played by pure and applied research in advancing engineering education and its continued relevance and applicability for numerous facets of research by academics all across the world.

LITERATURE REVIEW: Analysing the Role of Pure and Applied Research in Engineering Education

The publication, UK Essays (1970) opines that educational research is important because it provides trustworthy information regarding educational problems and their solutions. Research is the combination of experience and reasoning and is the most effective approach to truth discovery (Borg, 1963, as cited in Cohan, Manion, \& Morrison, 2000). Educational research is a 'purposeful and systematic' enquiry 'to solve a problem, illuminate a situation or add to our knowledge' (Mutch, 2005, pp. 14) 'by the discovery of nontrivial facts and insights' (Howard \& Sharp, 1983, as cited in Bell, 2005, pp. 2) 'in relation to the improvement of education policy and practices, with a commitment to broader 
dissemination of research findings beyond publication in high status, international, refereed journals' (Lingard \& Gale, 2010, pp. 31).

The process of solving problems via practical application begins with understanding the core concepts, principles and ideologies of engineering and customizing or personalizing research to solve a particular problem in line with the country's innovative, design and structural goals and needs. The results of engineering research apart from leading to innovation spreads knowledge as it is often circulated in journals, at academic conferences, and as new products on the market. It can initiate conversations about processes and systems, resulting in necessary adjustments, upgrades and reviews. The key to a successful research project lies in iteration which is the process of repeatedly returning to the research questions, data and methods which leads to new ideas, improvements and revisions. Technology is constantly evolving and academic discussions regularly lead to additional research questions and numerous other changes. A good research study has its data and methodology reviewed and re-examined from several perspectives which leads to a transformation in the direction of research. This ensures a comprehensive approach to the research question. The research process is iterative and cyclical with no particular formula for a successful study (Unite for Sight, 2015) and variables like user compatibility and adaptability to numerous operating conditions, cost and safety must be accounted for in the designing and development phase. Engineering students often focus on research practicability for ease of application in real life innovation and problem solving in their careers (Academies Press, 1995).

Engineering research involves utilizing more advanced analytical and experimental methods across all areas of engineering to address the best teaching methods, effective design of learning environment, material to be taught and information that should be included in engineering education. Pure research explores the problem, laws, methods, techniques, basic phenomenon and fundamental principles of a research subject. It examines the pedagogical significance and structure of research contents and is also concerned with the discovery and systematic conceptual structuring of knowledge. It also teaches students to approach design problems in a systematic way by applying a systematic approach in analysing the objectives and planning alternative solutions to reach the desired goal (Bernhard). Pure research is conducted without any specific goal in mind with the aim of advancing knowledge and establishing or analysing the relationship between variables. It enhances fundamental knowledge and introduces new principles, theories and ideas. Pure research is the source of the majority of new knowledge and ideologies in the world. It is driven by curiosity, intuition, and interest, and is more exploratory in nature than applied research. It sometimes acts as a foundation for applied research because knowledge obtained from pure research is acted upon in applied research.

Unlike pure research, applied research is carried out in order to solve a specific and practical problem, it is therefore often descriptive in nature and is also mostly based on pure research. Applied research in solving practical problems often utilizes empirical methods and is used in various fields including technology and education. Studies under applied research always have a specific goal. Moreover, the results of applied research are usually intended for present use, not for future. It is also important to note that applied research studies are always based on the information or theories discovered through basic research.

What differentiates pure and applied research is the goal of the research. Pure research is conducted without any specific goal but it identifies and advances knowledge and contributes to the formulation of new theories and principles, while applied research aims to solve a specific and practical problem and is also based on the theories, principles and findings discovered through pure research (University of Southampton, 2017). The main aim of pure research is to advance knowledge while applied research is aimed at solving a particular and practical problem, therefore pure research is exploratory in nature while applied research is descriptive in nature. Findings of pure research usually have a future use, not a current use while applied research findings always has an immediate use.

There is a growing engagement of academics in applicationoriented and commercially funded research, but the extent of such engagement is limited based on the closeness of one's discipline to the market (Slaughter and Leslie 1997). This shift in research agenda away from pure research is proof that universities are no longer focused on theoretical research, although academics still consider it to be a core part of their current research. Most academics specialise only in basic or applied research, or a combination of both and the extent of engagement in either one depends on access to external commercial research funding; institutional expectations/policies; and individual normative/social behaviour. Nowotny et al. (2003) posit that the causes for the decline in fundamental research include; increased steering of research priorities; increased commercialisation of research (resulting from decreased public funding and increased attention to intellectual property ownership); and broader accountability of science.

A large-scale Finnish investigation as well as a UK interview study both found that an "academic orientation" with strong emphasis on basic research remains at the core of research across disciplinary fields (Ylijoki et al. 2011). The authors question the point that focus is shifting from pure research in universities arguing instead that academics find different ways to combine an academic orientation with various forms of societal engagement, helped by the fact that pure research is perceived as flexible and adaptable to varying circumstances (Calvert 2006). Gulbrandsen and Kyvik (2010) also found that $90 \%$ of Norwegian academics undertook basic research, with slightly less than half declaring their research "very much", basic (maximum value on a five-point scale), confirming other findings that basic research remains a strong identity marker for university staff (Gulbrandsen and Langfeldt 2004). These results are indicative of the resilience of basic research within universities.

From the definition and description of both types of research which are similar to students knowledge requirements, it can be surmised that a lot of the theoretical knowledge passed on to engineering students is generated through pure research while applied research provides them with the practical knowledge 
and skills required to resolve specific issues. It can therefore be inferred that both forms of research work together and are essential to engineering education in today's world. Pure and applied research are at the core of academic and specifically, engineering education and this is evidenced by their high adoption rate by academics all over the world.

\section{PURE AND APPLIED RESEARCH AS THE FOCAL POINT OF RESEARCH IN ENGINEERING EDUCATION}

In examining the relevance of research in engineering education, a question that must be addressed is; to what extent is pure and applied research a defining characteristic of research in engineering education?

The majority of academics engage in basic research but an even greater proportion engage in applied research. To this extent, pure research may not be the primary preoccupation of universities, even though the majority engage in it. According to findings from a research carried out by Bentley et al (2015) More than two-thirds (69\%) of academics characterised their research as applied to a large extent, one quarter $(25 \%)$ were partly engaged in basic research, and $6 \%$ not at all. China was again the country where academics were most likely to report strong engagement in applied research $(86 \%)$. Norway and the Netherlands were the only countries where a significantly higher number of academics engaged more in pure research than applied research. According to Bentley et al (2015) when asked to characterise the emphasis of their primary research in the previous year $61 \%$ of academics surveyed reported significant engagement in pure research, $7 \%$ engaged in pure research, while $32 \%$ were partly engaged in pure research. Consequently, Nowotny et al (2003) submission that pure research is a minority preoccupation in universities received limited empirical backing with $93 \%$ engaging in pure research. Levels of significant engagement in pure research ranged from $78 \%$ in China to $50 \%$ of all academics in Argentina.

Pure research is motivated by a desire to expand knowledge and aspires to acquire knowledge with no other motive but to learn. It strives to answer the 'why, what or how' questions and increase understanding of fundamental principles. Pure research is not commercially inclined initially unlike applied research and may not necessarily result in an invention or problem solving. Applied research on the other hand, is designed to answer specific questions aimed at solving practical problems. New knowledge acquired from applied research has specific commercial objectives in the form of products, procedures or services. Fundamental research answers the initial question of how things work (University of Texas). The aim of basic research is to improve scientific theories for better understanding or prediction of natural or other phenomena, while applied research uses scientific theories to develop technology or techniques to intervene and alter natural or other phenomena. Pure research fuels applied science's innovations and both aims are often coordinated in research and development. Basic research focuses on creating and refuting or supporting theories that explain observed phenomena. Pure research is the source of most new scientific ideas and ways of thinking about the world. It can be exploratory, descriptive , or explanatory with explanatory research being the most common. Basic research generates new ideas, and theories, often not immediately translated into something but which eventually forms the basis of progress and development in numerous fields. Today's computers, would not exist without research in pure mathematics conducted over a hundred years ago, for which there was no known practical application at the time.

In the U.S pure research is funded mainly by federal government and done mainly at universities and institutes. It develops scientific knowledge and predictions, majorly in natural sciences and some empirical sciences, which are used as the scientific foundation for applied science. Basic science develops and establishes knowledge to predict phenomena and understand nature, while applied science uses portions of basic science to develop interventions via technology or technique to alter events or outcomes.

Applied and basic sciences can interface closely in research and development . The interface between them has been studied by the National Science Foundation. It conducted a study in which it traced the relationship between basic scientific research efforts and the development of major innovations, such as oral contraceptives and videotape recorders. The study found that basic research played a major role in the development in all of the innovations with the number of basic science research that assisted in the production of a given innovation reaching as high as between 20 and 30 years before the innovation itself. While most innovation takes the form of applied science and most also occurs in the private sector, about $76 \%$ of basic research is being conducted by universities, hence pure research is a necessary prelude to almost all applied science and associated innovation opportunity, which answers the question; how relevant is pure and applied research for students? Undergraduate research is useful for improving student retention as well as helping them determine a career path. A survey undertaken by the American Society for Engineering Education involving 26 engineering students involved in undergraduate research work and a few faculty members records both students and faculty mentors as acknowledging the impact of undergraduate research experiences (American Society for Engineering Education, 2016).

Research in engineering education is necessary for academia and students in general but even more essential is the integration of pure and applied research methods which is vital for enhancing student engagement and enriching student learning experiences.

Pure and applied research helps students or researchers acquire better problem-solving and conceptualization skills. To achieve the research objective which is mostly solving a specific problem, applied research is often adopted, but knowledge already acquired from pure research is often necessary and utilized to initiate and successfully execute applied research. Pure research helps the researcher identify, assess and collate all the necessary information which is often stored for future use in executing applied research with the aim of resolving a specific problem. This problem solving need explains why academics favour applied over pure research but still require some measure of pure research to effectively execute research. 
The objective of pure research lines up with the end goals of the students which is proffering solutions used for simplifying concepts into main ideas and then applying strategies and techniques learned to applied research to create workable solutions. Being able to distinguish and evaluate all the data improves conceptualization, translating to effective and efficient ideas. This is done through pure research which is engaged in majorly for knowledge advancement and is crucial to university missions. The "linear model" of innovation acknowledges pure research as the main contributor to innovation and economic growth (Mowery and Sampat, 2005). Applied research nurtures innovative skills which will be useful for a student's careers in the future as it focuses on the development of technology and techniques essential for a career in engineering. Quality control which is a part of applied research enables academia maintain good quality standard in research output and processes due to the role of peer review in validating new knowledge in educational research.

Academic research, as vital as it is to engineering education and its application, is plagued by several factors that hinder its widespread practice in engineering faculties across the world, especially in developing countries. These challenges include; inadequate funding for research, poor equipment and infrastructures, poor practices in academic staff recruitment and training resulting in staff that are underqualified to spearhead effective research work, curriculum epistemicide which hinders problem solving through exploration of indigenous challenges in favour of an Eurocentric orientation and approach to studies. Another major issue is the disconnect or poor collaboration between government-industries-higher institutions, this prevents students and academic researchers from gaining an insight into current technological challenges which would provide much needed insight and point them in the right direction for research studies. These issues have to be rectified to create an enabling environment for effective research to occur. Also key is the establishment of a single professional accreditation body for engineers, academicians and students to ensure the maintenance of quality in engineering education and research.

Engineers now face the universal challenge of managing issues among social, economic, ecological, and intellectual capital (Hawthorne et al., 2012) (Bertus et al., 2012) (Ahmed et al., 2012). The knowledge to effectively manage these issues can only be acquired through proper education and innovation which stems from proper research, and pure and applied research are a key part of this knowledge acquisition for effective management of these capital particularly as both forms of research outline clear research procedures that often end in the desired result, whether it is knowledge acquisition or specific solutions to a problem. The issue of capital management and utilization can be resolved through pure research which will yield necessary solutions to technical know-how questions while applied research will proffer solutions to specific innovation and application challenges. The importance of both types of research is not in question in engineering education thus they are common, often preferred and adopted research techniques, although specialisation in applied research is more common in engineering. The goals of pure and applied research often serves the objective of engineering research and practice which is to establish new knowledge and solve specific problems. It can hence be surmised that both forms of research are vital for equipping students with the knowledge and skills they need to be effective engineers. Both forms of research are thus essential for maintaining an effective engineering education system in institutions across the world.

\section{THE INDISPENSABILITY OF PURE AND APPLIED RESEARCH IN $21^{\text {ST }}$ CENTURY ENGINEERING EDUCATION}

A survey carried out by Bentley, P; Gulbrandsen, M; Kyvik, S. (2015) revealed that $3 \%$ of academics in universities around the world carry out pure research while $21 \%$ concentrate on applied research in engineering. National governments are the main source of university research funding in almost all OECD countries, varying from over $80 \%$ of total funding of $R \& D$ in higher education institutions in Norway, Italy, Germany, Argentina, Finland, Australia, and the Netherlands to closer to two-thirds in the UK, USA and Canada, and a little over 50\% of funding in China (OECD 2013). Basic and applied research are types of practical research, further divided into three types of research namely; quantitative, qualitative and mixed research. Other types of research include; descriptive research, longitudinal, Cross-sectional and action research. Before the advent of pure and applied research, the scientific method was used to carry out research. Prior to the past decade, government agencies, scientists and research institutions relied solely on a system of self-regulation based on generally accepted research practices to ensure integrity in the research process. The decline in public funding via education sector allocation puts the future survival of pure research in jeopardy in many countries, with the only hope for its survival in the US being the return of federal funding that will support pure research projects and this is unlikely to happen. U.S spending on science as a percentage of total government budget fell from over $10 \%$ in 1964 to less than 6\% today, consequently, basic research projects are abandoned for corporations with no interest in funding new research.

Part of the principles that guide scientists and scholars are those expressed as respect for the integrity of knowledge, collegiality, honesty, objectivity, and openness. These principles are at work in the fundamental elements of the scientific method which was the prevalent research method before the emergence and wide adoption of pure and applied research. Some ongoing and future engineering projects currently being researched include; faster planes that run on new types of fuel, autonomous machines to harvest crops with precision at ideal times, more efficient energy usage and new , more efficient methods of waste recycling, improved imaging techniques for faster diagnosis of illnesses, refined bionic implants, artificial blood, new modes of transportation, new technologies such as self-driving cars, creating super-fast quantum computers, offsetting carbon emissions to counteract damage to the environment, building structures that float and generating energy from ocean waves and machines that can rid our oceans of plastic waste. All these projects are being executed with information gleaned from pure research. 
Nowotny et al (2003) argument that inadequate public funding in most countries has caused the shift away from basic research in most universities is supported by the fact that since government funding of research has decreased in some OECD countries, and the criteria for receiving public funds changed from consistent block grants towards results-based models, pure research has declined drastically in most countries. Auranen and Nieminen (2010) postulate that pure research yields unforeseen results, and as a result attracts limited private sector funding, thus access to private funding also affects type of research embarked on. Academics with access to private funding (business and industry funding) for research are not as dependent on institutional funding and are more likely to engage in applied research. Universities also struggle to meet stakeholder expectations particularly in terms of producing practical knowledge and training. Clark (1998) sums up the situation in terms of a demand-response imbalance, he opines that demands on universities outweigh their capacity to respond. Consequently, academics in such situations are prone to engaging in applied research. Altbach (2001), states that the future of pure research is in danger as the availability of funding changes, especially in terms of the independence and protection of research from being influenced by external forces.

In $R \& D$ intensity (ratio of $R \& D$ to gross domestic product [GDP]), the US ranked 10th in 2017. The R\&D-intensity level has seen moderate growth in the US since 2000, while South Korea and China have recorded rapid increases. Total global R\&D expenditures have also increased considerably, tripling between 2000 (\$722 billion) and 2017 (\$2.2 trillion). Global R\&D activity remains concentrated in the United States, EU, and the combination of East-Southeast and South Asia regions. According to data from the National Science Foundation and the National Centre for Science and Engineering Statistics, the United States was the largest R\&D performer in 2017. However, its global share since 2000 fell as R\&D spending increased in China and several other Asian countries. China, whose R\&D spending has now surpassed that of the EU is in second place. Together, the US (25\%) and China (23\%) accounted for nearly half of the estimated global R\&D total in 2017. Japan (8\%) and Germany $(6 \%)$ come next, then South Korea (4\%). France, India, the United Kingdom, Russia, Brazil, Taiwan, Italy, Canada, Spain, Turkey, and Australia account for about $1 \%-3 \%$ each of the global total. Numerous other countries also conduct R\&D, with annual expenditures well below these listed countries. The current fund expenditures for research equipment in engineering faculties at academic institutions in the US rose from $\$ 394,000,000$ in 2004 to $\$ 594,000,000$ in 2018 with the federal government contributing $56.4 \%$ of the amount in 2004 and $44.5 \%$ in 2018. While academic basic research in the US declined from $57.19 \%$ in 2004 to $48.44 \%$ in 2017 applied research rose from $12.89 \%$ in 2004 to $18.39 \%$. Science and engineering research space in US academic institutions has also grown from 185.1 in 2005 to 220 in 2017. Also US academic research and development expenditure in engineering rose from 14.7 in 2008 to 15.6 in 2018.

Pure research is an integral part of academic work at most research universities across the world. A whooping $61 \%$ of academics from data material based on more than 10,000 researchers from 15 countries report significant engagement in pure research, and only $7 \%$ report no engagement in basic research. While it is evident that basic research is an essential part of research in most universities across the world, more academics however, carry out applied research than basic research. Even in cases where academics are seen to engage in both types, there is a clear preference as more engage in applied research over basic, proving the point that pure research is essential to academic research but often secondary to applied research.

According to Gulbrandsen and Kyvik (2010) pure research is also preferred in Finnish and Norwegian universities. (see Ylijoki et al. 2011; Gulbrandsen and Kyvik 2010), academics in Norway and the Netherlands favoured basic research over applied research. Both types of research were equally favoured in Italy but these countries were the exceptions. Applied research was the preferred choice of research in most countries, particularly in Australia where academics were twice as likely to favour applied research, same as USA and Hong Kong. Research commercialisation were weakest in Mexico, Argentina and Brazil, and relatively weaker in most European countries. The UK also favours applied research, same as Brazil and Argentina which are moderately engaged in applied research but even less engaged in basic research. Latin American university discourse favours applied research but the academic evaluation system remains entrenched in pure research (Arocena and Sutz 2001, p. 1231).

\begin{abstract}
Although neither Malaysia nor China have strong university research traditions they expressed strong self-characterisations in both forms of research and their governments have recently expressed increased interest in basic research as a way of pursuing innovation and development goals (ZhuandGong2008; Leeetal.2013).
\end{abstract}

The centrality of basic research has been dispelled and it is now the general opinion that academic-oriented, disciplinary and autonomous research carried out wholly within universities is no longer the major mode of knowledge production. Applied knowledge, which is produced within the context of application is currently the dominant form of knowledge production. Nowotny et al. (2003) opines that pure research is now a minority preoccupation - even in universities' (p. 184) and its decline brought about the emergence of applied research which is more transdisciplinary and collaborative. But critics have pointed out its lack of coherence and empirical validity (Hessels and Van Lente 2008).

\section{METHODOLOGY}

The research methodology is based on a literature review of descriptive information. This study utilized a qualitative data collection technique by reviewing and drawing information from surveys, papers and articles published between 1970 2020 to establish the importance of pure and applied research for engineering education across countries and higher institutions. The study examined 31 publications authored by academia and experts and adopted a descriptive methodology to review these journals and papers in the course of establishing the role of pure and applied research methods in engineering 
education. These papers were sourced through an internet search utilizing some keywords. The search terms used are; pure research OR applied research OR engineering education OR research.

\section{FINDINGS}

This study established that both pure and applied research continue to be relevant forms of research in engineering education with most academics focusing more on applied research in educational institutions across the world. There is also a level of interdependence between both forms of research with pure research figuring out how things work and applied research using these answers to upgrade existing products, processes and technology and innovate new ones as well.

\section{CONCLUSION}

This study surmised that both forms of research often go together as pure research enhances foundational knowledge and provides a richer body of data for applied research to build on. Also, the workings of pure and applied research align with the 'blue print' for knowledge, acquisition, assimilation and practice in academia. Both forms of research are student friendly in their simplicity and effectiveness and are thus widely adopted by academia. Also, the type of funding available to academia affects the type of research they engage in, hence engineering researchers in academia accessing private funding are more likely to engage in applied research over pure research. The developed countries also engineering academia have higher research budgets from both public and private sources and consequently record a much higher rate of research than their counterparts in developing countries.

\section{RECOMMENDATION}

Countries with low levels of research will experience slower development than its research - driven counterparts and be technologically dependent on other countries. This study recommends that government and the private sector partner with engineering faculties especially in developing countries and channel adequate funding to research in science, technology and engineering as research is the primary way knowledge can be acquired and innovation can be nurtured. Also, research should be structured to maximize student learning experience and new technology should be explored in the research process for faster and more efficient solutions. Students should also be taught how to determine the best research method to adopt in order to achieve the research objective and appropriate interface of pure and applied research components where necessary, to yield more effective results. Research techniques should be optimized and aspects of modern educational technology like collaborative learning should be explored to maximize learning experience.

\section{CONTRIBUTION OF NEW KNOWLEDGE}

Modern technology can bring an invaluable contribution to research in terms of collaborating with academics across the world. Engineering faculties should take advantage of modern technology and explore the possibility of livestreaming research work to their counterparts across countries especially the developing countries that may not have the budget to carry out intensive, large scale research. This will enable students explore current trends in technology in real time which avails them of the opportunity to ask questions. Most studies use only a single research method. However, the combination of both or multiple research methods is expected to produce more reliable results so academics in engineering should explore the option of research utilizing multiple research methods for a more thorough research work and teach students how to execute this as well.

\section{REFERENCES}

[1] Academies Press (1995) Forces Shaping the U.S. Academic Engineering Research Enterprise. Retrieved from: https://www.nap.edu/read/4933/chapter/3

[2] American Society for Engineering Education (2016). 2016 ASEE Annual Conference \& Exposition. Importance of Undergraduate Research: Efficacy and Student Perceptions Presented at Mentoring, Advising, and Facilitating Learning. Retrieved from: https://www.asee.org/public/conferences/64/papers/144 88/view

[3] Altbach, P. G. (2001). Academic freedom: International realities and challenges. Higher Education, 41(1-2), 205-219.

[4] Arocena, R., \& Sutz, J. (2001). Changing knowledge production and Latin American universities. Research Policy, 30, 1221-1234.

[5] Auranen, O., \& Nieminen, M. (2010). University research funding and publication performance-An international comparison. Research Policy, 39(6), 822834. doi:10.1016/j.respol.2010.03.003.

[6] Bentley, P., Gulbrandsen, M., Kyvik, S. (2015). The relationship between basic and applied research in universities. Retrieved from: https://nifu.brage.unit.no/nifuxmlui/bitstream/handle/11250/281592/Basic_applied_r esearch.pdf?sequence $=6 \&$ isAllowed $=\mathrm{y}$

[7] Bernhard, J. Is Engineering Education Research Engineering? Retrieved from: https://www.divaportal.org/smash/get/diva2:633766/FULLTEXT01.pdf

[8] Clark, B. R. (1983). The higher education system. Berkeley: University of California Press.

[9] Clark, B. R. (1998). The entrepreneurial university: Demand and response. Tertiary Education and Management, 4(1), 5-16.

[10] Engineers Australia. The future of Engineering. Retrieved from: https://www.engineersaustralia.org .au/For-Students-And-Educators/EngineeringCareers/Future-Of-Engineering 
International Journal of Engineering Research and Technology. ISSN 0974-3154, Volume 13, Number 9 (2020), pp. 2402-2408

(C) International Research Publication House. https://dx.doi.org/10.37624/IJERT/13.9.2020.2402-2408

[11] Falade, F. (2016). Advancement of Engineering Education in Africa: AEEA Perspective. Retrieved from: http://www.ifees.net/dvancement-of-engineeringeducation-in-africa-aeea-perspective/

[12] Gulbrandsen, M., \& Kyvik, S. (2010). Are the concepts basic research, applied research and experimental development still useful? An empirical investigation among Norwegian academics. Science and Public Policy, 37(5), 343-353.

[13] Gulbrandsen, M., \& Langfeldt, L. (2004). In search of Mode 2: The nature of knowledge production in Norway. Minerva, 42, 237-250.

[14] Kyvik, S. (2007). Changes in funding of university research. Consequences for problem choice and research output of academic staff. In J. Enders \& B. Jongbloed (Eds.), Public-private dynamics in higher education: Expectations, developments and outcomes (pp. 387411). Bielefeld: Transcript Verlag.

[15] Nowotny, H., Scott, P., \& Gibbons, M. (2003). Introduction: 'Mode 2' revisited: The new production of knowledge. Minerva, 41(3), 179-194. doi:10.1023/a:1025505528250.

[16] National Institute of General Medical Sciences (2020). What is basic science and why is it important? Retrieved from: https://www.nigms.nih.gov/education/factsheets/Pages/curiosity-creates-cures.aspxUniversity of Southampton. Types of Research. EResearch Methods (2017).

[17] Hasa (2017) Difference Between Pure and Applied Research. Retrieved from: https://www.differencebetween.com/differencebetween-pure-and-vs-applied-research/

[18] International Network for Natural Sciences (2020). Types of Scientific Research. Retrieved from: https://innspub.net/types-of-scientific-research/

[19] Research Methods for the Social Sciences (2020). Science and Scientific Research. Retrieved from: https://courses.lumenlearning.com/suny-hccc-researchmethods/chapter/chapter-1-science-and-scientificresearch/Research Methods for the Social Sciences

[20] Science Buddies. Comparing the Engineering Design Process and the Scientific Method. Retrieved from: https://www.sciencebuddies.org/science-fairprojects/engineering-design-process/engineeringdesign-compare-scientific-method
[21] National Science Foundation. Science and Engineering Indicators. Retrieved from: https://ncses.nsf.gov/pubs /nsb20202/data

[22] Unite for Sight 2015). Module 6: The Importance of Research

[23] Retrieved from: http://www.uniteforsight.org/researchmethodology/module6

[24] University of Texas. Basic vs. Applied Research. Retrieved from: https://www.utep.edu/couri/about-ugresearch/basic-vs-applied-research.html

[25] Get Trained (2020). Why Engineering is so Important to Society. Retrieved from https://get-trained.org/latestnews/why-engineering-so-important-society

[26] Noble Precision (2020). Importance of Research Skills for Engineering Students. Retrieved from: https://www.nobleprecision.com/importance-ofresearch-skills-for-engineering-students/

[27] Office of Research Integrity (ORI) What is Research? Retrieved from: https://ori.hhs.gov/module-1introduction-what-research

[28] Responsible Science: Ensuring the Integrity of the Research Process: Volume I (1992)

[29] Chapter: 2 Scientific Principles and Research Practices. Retrieved from: https://www.nap.edu/read /1864/chapter/4

[30] UK Essays (1970). The Role And Importance Of Educational Research Philosophy Essay. Retrieved from:

https://www.ukessays.com/essays/philosophy/the-roleand-importance-of-educational-research-philosophyessay.php

[31] Your Dictionary staff. Examples of Applied Research Topics. Retrieved from: https://examples.yourdictionary .com/examples-of-applied-research.html

[32] Ylijoki, O.-H., Lyytinen, A., \& Marttila, L. (2011). Different research markets: A disciplinary perspective. Higher Education, 62(6), 721-740. doi:10.1007/s10734011-9414-2.

[33] Zhu, Z., \& Gong, X. (2008). Basic research: Its impact on China's future. Technology in Society, 30(3-4), 293 298. doi:10.1016/j.techsoc.2008.05.001. 